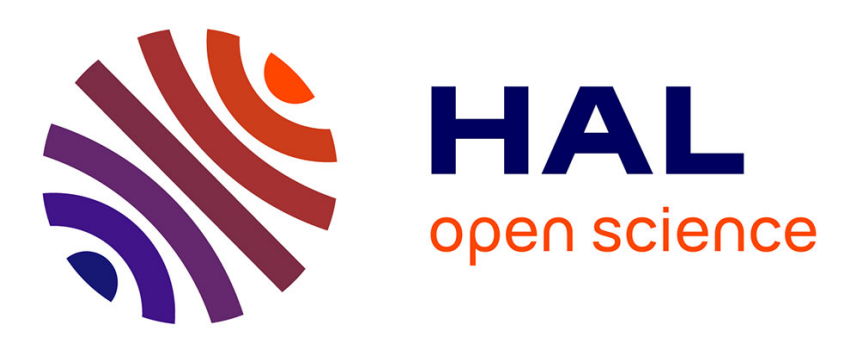

\title{
Lipidome variations of deep-sea vent shrimps according to acclimation pressure: A homeoviscous response?
}

\author{
B. Shillito, J. Ravaux, M. Zbinden, C. Desurmont, D. Barthélémy, D. \\ Farabos, G. Després, A. Lamazière
}

\section{- To cite this version:}

B. Shillito, J. Ravaux, M. Zbinden, C. Desurmont, D. Barthélémy, et al.. Lipidome variations of deepsea vent shrimps according to acclimation pressure: A homeoviscous response?. Deep Sea Research Part I: Oceanographic Research Papers, 2020, 161, pp.103285. 10.1016/j.dsr.2020.103285 . hal03330586

\section{HAL Id: hal-03330586 \\ https://hal.science/hal-03330586}

Submitted on 3 Sep 2021

HAL is a multi-disciplinary open access archive for the deposit and dissemination of scientific research documents, whether they are published or not. The documents may come from teaching and research institutions in France or abroad, or from public or private research centers.
L'archive ouverte pluridisciplinaire HAL, est destinée au dépôt et à la diffusion de documents scientifiques de niveau recherche, publiés ou non, émanant des établissements d'enseignement et de recherche français ou étrangers, des laboratoires publics ou privés. 


$$
4
$$

Shillito, B. ${ }^{\mathbf{1}^{*}}$, Désurmont, C. ${ }^{\mathbf{1}, \mathbf{2}}$, Barthélémy, D. ${ }^{3}$, Farabos, D. ${ }^{2}$, Despres, G. ${ }^{\mathbf{2}}$, Ravaux, J. ${ }^{\mathbf{1}}$, Zbinden, M. ${ }^{1}$, Lamazière, A. ${ }^{2}$

1 Laboratoire de Biologie des Organismes et Ecosystèmes Aquatiques (BOREA), MNHN, CNRS-2030,

7 IRD-207, Sorbonne Université, UCN, UA

2 Sorbonne Université, INSERM, Centre de Recherche St-Antoine, CRSA, Département de Métabolomique

Clinique, Hôpital Saint Antoine, AP-HP, F-75012 Paris France

3 Océanopolis, Port de Plaisance du Moulin Blanc BP 91039, 29210 Brest Cedex1, France

\begin{abstract}
The present study questions the ability of marine fauna to modulate the molecular composition of their membrane lipids, as a function of environmental hydrostatic pressure conditions. Specific variations in the cell lipidome composition are presented for the deep-sea hydrothermal vent shrimp Mirocaris fortunata, acclimated at the laboratory for several months at both natural (18 MPa) and atmospheric pressures, but fed with the same diet. These animals display physiological capabilities of acclimation to pressure variations, possibly driven by a particular composition of their lipid species. In particular, it is shown that shrimps exposed to atmospheric pressure exhibit a significantly lower level of the mono-unsaturated fatty acid, vaccenic acid (C18:1n-7), compared to those maintained at natural pressure. The observed fatty acid variations are consistent with a homeoviscous response, i.e. a modulation of the lipidome composition, in response to physical constraints, in order to balance the effects of pressure on membrane order. Additionally, supervised multivariate data analysis was performed for complex lipids and revealed an increase in levels of sterols, sphingomyelin, and ether-phosphatidylethanolamine lipids for animals exposed to atmospheric pressure, with respect to natural pressure. These observations strongly suggest that lipidic domains are involved in the shrimp's response to experimental conditions, and their consistency with a homeoviscous response to pressure is discussed.
\end{abstract}


30

31 32

KEY WORDS : Hydrothermal vent shrimps, Pressure tolerance, Viscosity, Homeostasis, Homeoviscous, Lipid signature, Lipidomes, AbyssBox

\section{(*) : Corresponding author}

e-mail : Bruce.Shillito@upmc.fr

postal address : B. Shillito, équipe AMEX-BOREA, Sorbonne Université, 7 Quai Saint-Bernard, Bâtiment A, 4ème étage, Paris 75005, FRANCE

Competing interests statement : The authors declare that they have no known competing financial interests or personal relationships that could have appeared to influence the work reported in this paper.

Contributions of authors : BS designed the acclimation experiments, BS CD and AL wrote the manuscript, which was further reviewed by all authors. MZ JR DB supervised in situ sampling, transport, and maintenance of deep-sea shrimps, JR and MZ undertook conditioning of samples at the end of the acclimation period. DF GD AL undertook the determination of lipidomes by GC-MS, and CD AL carried out statistical analyses of data. 


\section{INTRODUCTION}

Marine depths exceeding 1000 m occupy about $75 \%$ of the global ocean volume. The deep sea is therefore probably the largest biotope on earth (Fang et al., 2010), and discoveries in the last decades have brought the picture of a high biodiversity environment (Ramirez-Llodra et al., 2010). Along with these findings, another emerging view is that the deep sea has been the subject of successive colonisation events by shallow water species, spread over geological times (reviews in Priede \& Froese, 2013, Brown \& Thatje, 2014), and the opposite phenomenon (from deep to shallow waters) is also likely (Barnes \& Kuklinsky, 2010, Brown \& Thatje, 2014). The pace at which such migratory events occurred remains unknown : is it a "slow" phenomenon submitted to evolutionary speciation, or a "fast" one, driven by the migration of individual specimens capable of acclimatisation to new environmental conditions?

The existence of a depth zonation in the distribution of extant species, possibly explained by a genetically constrained physiological tolerance regarding hydrostatic pressure variations (Carney 2005, Brown \& Thatje 2014) would support the first hypothesis. Hydrostatic pressure in the marine biosphere increases linearly with depth, ranging from $0.1 \mathrm{MPa}$ at sea level (i.e. the so-called "atmospheric pressure"), to about $110 \mathrm{MPa}$ in the deepest trenches, at a depth of about $11000 \mathrm{~m}$ (Jamieson et al., 2010). Several studies have long documented severe impacts on behavioral and motor activity, and survival, either during pressurization experiments on shallow-water organisms (review in Pradillon 2012, Ammendolia et al., 2018), or by observations of decompressed deep-sea animals following their recovery at depth (reviews in MacDonald, 1997, Somero 1992). Furthermore, in vitro experiments have also established that pressure variations in the 10-50 MPa range impact on many aspects of biological systems, such as enzyme function, or trans-membrane signaling (reviews in Somero 1992, McDonald, 1997, Pradillon 2012). So, although other environmental parameters may vary between habitats at different depths (i.e. light intensity, temperature, food availability, oxygen levels, etc.. (Ramirez-Llodra et al., 2010)), and thereby possibly control the distribution of a species (Brown \& Thatje, 2015), pressure alone would seem sufficient to restrict the occurrence of a species within a given depth range.

Some studies have opened the way to another (non-exclusive) hypothesis: direct colonisation by specimens capable of acclimatisation to new environmental conditions. Some in situ studies have reported spectacular bathymetric migrations, such as that of antarctic krill (E. superba, from the surface to a depth of beyond 3000 m, Clarke \& Tyler, 2008), or Mediterranean red shrimp (Aristeus antennatus, depth from $80 \mathrm{~m}$ to $3300 \mathrm{~m}$, Sarda et al., 2004). More recently, laboratory studies have shown that some shallow-water invertebrates could survive for several days at 
pressures far beyond those encountered in the wild: the ditch shrimp Palaemonetes varians, exclusively reported in depths of less than $1 \mathrm{~m}$, presented survival of $70 \%$ after 28 days at a simulated depth of $1000 \mathrm{~m}$ (10 MPa, Cottin et al., 2012). Finally, the deep-sea hydrothermal vent shrimp Mirocaris fortunata, the subject of the present study, not only displays an important distribution of depth (from 850 to 4050 m, Desbruyères et al., 2006, Fouquet et al., 2008), but has also been successfully acclimated for several months at atmospheric pressure (Shillito et al., 2015), far out of its reported natural bathymetric range. It has been argued that the potential to undertake bathymetric migration may be species-specific, suggesting there may be "winners and losers" in the face of near-future climate-driven migration patterns (Ammendolia et al., 2018, Brown \& Thatje, 2015). In other words, some species would be able to display physiological plasticity in response to pressure variation (i.e. capable of acclimatisation), while others would not. Comparison between deep and shallow species point at a number of biological features which respond to pressure conditions, such as protein functioning (Pradillon, 2012) or osmolyte levels (Yancey et al, 2013), but most importantly, the molecular composition of biological membranes has long been identified as a highly pressure-sensitive feature (review in Hazel \& Williams, 1990).

Biological membranes are a complex and dynamic assembly of lipids and proteins, and as for temperature, variations in hydrostatic pressure can modify the conformation and packing of the molecules composing these liquid-state lipidic bilayers, thereby impacting their molecular order. However, pressure and temperature effects appear to be in opposition: an increase in pressure tends to increase membrane order (i.e. "rigidifies" the membrane), while an increase in temperature lowers membrane order (i.e. "fluidizes" the membrane). Living organisms respond to such perturbations by modulating the molecular composition of their membranes, in order to oppose to the deleterious (ordering or disordering) effects of the environmental change, thereby allowing to maintain membrane order, and therefore cellular homeostasis (Hazel, 1995, Ernst et al., 2016). This response is termed "homeoviscous", and was first observed regarding thermal variations in bacteria (Sinensky, 1974). Today it is widely accepted that all poikilothermic organisms (which do not control their temperature) may undertake such a response in the face of thermal variations, including within the lifespan of a given individual organism, i.e. as an acclimatory response (Parent et al., 2008, for example). The variations in membrane compositions of deep-sea animals submitted to different pressures were first evidenced by comparing different fish species originating from various depths (Cossins \& MacDonald, 1986, Behan et al., 1992). An important study also showed that a given bacterial strain would modify its membrane composition within a few days, according to incubation pressure (Delong \& Yayanos, 1985). Since then, much of our knowledge on the homeoviscous response to pressure has come from studies of bacteria (Wirsen et al., 1987, Allen et al., 1999, Grossi et al., 2010, Fumiyoshi, 2013, Wang et al., 2014, Cario et al., 2015), which are 
more amenable to pressure incubation than metazoans, mainly because of a limitation in pressure equipments suitable for large organisms. Therefore, our knowledge of the homeoviscous response to pressure in animals remains limited. One of the major remaining questions is whether the abovementioned "winners", i.e. species displaying acclimatisation capacities in response to pressure variation, are capable of a such a response.

Studies of the homeoviscous response to pressure have so far focused mainly on the study of the relative proportions of saturated fatty acids (SFA), mono-unsaturated fatty acids (MUFA), and poly-unsaturated fatty acids (PUFA) which compose the hydrophobic fraction of membrane lipids. Schematically, high levels of SFA increase membrane order, while the presence of one or several double bonds in MUFA and PUFA lead to disordered assemblies (Guschina \& Harwood, 2006). Therefore, organisms at high pressure are expected to display higher levels of unsaturated fatty acids and lower levels of SFA, thus counteracting the ordering effect of pressure, and a reverse situation is expected for exposure at low pressure. However, given the complexity of eucaryotic biomembranes, composed of several hundreds of different molecules, an emerging view is that the homeoviscous response is probably more complex than described up to now, and it is not only a matter of acyl chain composition. This view is supported by the growing outcome of contemporary quantitative lipidomics technology, which may allow to follow complex lipid changes during the homeoviscous response (review in Ernst et al., 2016). Finally, our understanding of the genetic and enzymatic regulation of the lipidomic response to pressure remains partial, and again owes much to studies of bacteria or yeast model organisms (Fernandes et al., 2004, Freitas et al., 2012). More generally, the way by which membrane homeostasis is achieved remains unclear (Ernst et al., 2018).

We here present results regarding the lipidomic compositions of the deep-sea shrimp Mirocaris fortunata, successfully acclimated at the public aquarium of Océanopolis at different pressure regimes (as opposed to "acclimatised" when occurring in the wild), in the context of a permanent public exhibition. Because of the importance in pressure variation between our experimental groups (18 MPa vs. atmospheric pressure), and because of the duration of the incubation in a controlled environment (several months, an exceptional situation regarding deep-sea fauna), our hypothesis was that potential lipidomic signature responses would be detectable, and that the additional use of high output lipidomics would help address the following questions :

1 - Are the observed successful acclimations accompanied by variations in lipidome composition, and if so, do these variations compare with homeoviscous responses documented in the literature?

2 - Beyond revealing classic characteristics of a homeoviscous response, could the complex lipid analysis bring original insights regarding the response to hydrostatic pressure? 
151

152

153

154

155

156

157

158

159

160

161

162

163

164

165

166

167

168

169

170

171

172

173

174

175

176

177

178

179

180

181

182

\section{Biological model}

This study focuses on the hydrothermal vent shrimp Mirocaris fortunata (Martin \& Christiansen, 1995). This species from the Alvinocarididae family is endemic to the Mid-Atlantic Ridge (MAR), where it can be encountered in proximity to vent openings, at temperatures around $10{ }^{\circ} \mathrm{C}$ (Desbruyères et al., 2001, Desbruyères et al., 2006, Matabos et al., 2015). Believed to be an omnivorous shrimp (Colaço et al., 2007), M. fortunata is found in great abundance on Bathymodiolus mussel beds, making its collection relatively easy. This species has a wide bathymetric distribution (850 m to $4050 \mathrm{~m}$ depth, Desbruyères et al., 2006, Fouquet et al., 2008), thereby providing a good model to investigate pressure-driven homeoviscous adaptations of deepsea organisms (Shillito et al., 2006). Moreover, several specimens originating from depths of 1700$1800 \mathrm{~m}$ have already been successfully acclimated in captivity for several years, both at in situ and atmospheric pressure at the Océanopolis public aquarium (Brest, France), (Shillito et al., 2015). These captive animals are the subjects of this study.

\section{Specimen collection, transport and maintenance}

Sampling of animals took place during two cruises, in July 2012 and 2013, respectively (Momarsat, 2012; Biobaz, 2013), on board the oceanographic vessels "Thalassa" (Momarsat, 2012) and "Pourquoi Pas?" (Biobaz, 2013) using the Remotely Operated Vehicle (ROV) Victor6000 (IFREMER) at the Lucky Strike vent field (MAR, 37¹7’6N, $1750 \mathrm{~m}$ depth). Specimens were sampled with a suction device operated by the hydraulic arm of the ROV. Immediately after recovery onboard the ship, the shrimps were stored at atmospheric pressure in tanks of approximately $5-101$ of aerated seawater in the cold room $\left(5-9^{\circ} \mathrm{C}\right)$, in groups of few individuals $(<5)$. At the end of the cruises, the shrimps were shipped to the Océanopolis public aquarium (air freight by "Flying Sharks", Lisbon, Portugal).

On arrival at Océanopolis, husbandry of the shrimps was performed by staff members of the aquarium. Most of the shrimps were acclimated at atmospheric pressure in a dark room $\left(10{ }^{\circ} \mathrm{C}\right)$ in groups of around $50 \mathrm{M}$. fortunata in $~ 801$ tanks each equipped with a $25 \mathrm{~W}$ heating element wrapped in PVC foam. This heater provides a localised "hotspot" with respect to the surrounding 10 ${ }^{\circ} \mathrm{C}$ environment, in the $13-28{ }^{\circ} \mathrm{C}$ range, in order to provide a thermal gradient mimicking their natural environment. Lights were switched on only a few minutes per day for cleaning, feeding and mortality counts. For the purposes of public exhibition, other individuals were maintained in a 16.5 1 pressurized aquarium named "AbyssBox" (described in Shillito et al., 2015), at a pressure of 18 
$\mathrm{MPa}$ (thereby simulating the pressure prevailing in the natural environment of these shrimps). The background temperature was set to $10^{\circ} \mathrm{C}$ by a temperature-regulation unit which cooled both the incoming water (flow rate of 10 1/hour) and the experimental vessel. As for atmospheric-pressure maintenance, a localized hotspot was provided for the shrimps, consisting of a ring-shaped tube heated to $27{ }^{\circ} \mathrm{C}$, wrapped in PVC foam. Because the pressurized shrimps were exposed to the public, they were submitted to about eleven hours of dim artificial light per day (see Shillito et al., 2015 and Matabos et al., 2015 for further details on shrimp maintenance and behaviour).

\section{Experimental design}

A first group (the BOX group) of five M. fortunata was maintained in the AbyssBox at a pressure of $18 \mathrm{MPa}$. The second group (the AP group) consisted of five $M$. fortunata maintained at atmospheric pressure. During the experiment which lasted five months, both groups were exclusively fed with Liptoaqua food pellets (Liptosa, Madrid, Spain) every $4-5$ days. These pellets were inert food (as opposed to live diet), apparently obtained from dried organic extracts, and their composition was not provided by the manufacturer. Shrimps in the AbyssBox were fed without decompression by an isobaric feeding line (see Shillito et al., 2015). At the end of the experiment, the shrimps ( $2-3 \mathrm{~cm}$ body length) were collected and dissected (immediately upon pressure release for the AbyssBox group). Abdominal muscle tissues and food pellets were subsequently frozen in liquid nitrogen.

\section{Lipid analysis}

\section{Fatty Acid Methyl Ester Analysis}

The frozen samples (muscle tissues and food pellets) were first homogenized using a tissue lyser apparatus (Quiagen, Les Ulis, France). A micro-method for total lipid extraction and methylation was applied from $20 \mu \mathrm{L}$ serum. Fatty acid methyl esters (FAME) were prepared and assayed by GC-MS in the positive chemical ionization mode with ammonia as the reagent gas (GC6890-MS5975; Agilent Technologies, Les Ulis, France) as described previously (Wolf \& Quinn, 2008). The response factors of fatty acids were calibrated with a weighed mixture (FAME Mix Supelco® 37, Sigma-Aldrich Chimie, L'Isle d'Abeau Chesnes, Saint Quentin-Fallavier, France). 25 fatty acids were detected and quantified. 


\section{Sterol Analysis}

Sterols in abdominal muscle tissue homogenates were extracted with a solvent mixture containing chloroform/methanol 2/1 (v/v) spiked with internal standards as described extensively elsewhere (Chevy et al., 2005). Briefly, lipids were partitioned in chloroform after the addition of saline and saponified by methanol potassium hydroxide $\left(0.5 \mathrm{~N}, 60^{\circ} \mathrm{C}, 15 \mathrm{~min}\right)$. The fatty acids released were then methylated with $\mathrm{BF} 3$-methanol $\left(12 \%, 60{ }^{\circ} \mathrm{C}, 15 \mathrm{~min}\right)$ to prevent from interfering with the chromatography of sterols. Sterols were further re-extracted in hexane and silylated, and the resultant derivatives were separated by gas chromatography (GC) (Hewlett-Packard 6890 series) in a medium polarity capillary column RTX-65, (Restesk, Evry, France). The mass spectrometer (Agilent 5975 inert XL) in series with the GC was set up for the detection of positive ions, which were produced in the electron impact mode at $70 \mathrm{eV}$. Sterols were identified by the fragmentogram in the scanning mode, and quantified by selective monitoring of the specific ions after normalization with the internal standards and calibration with weighed standards.

\section{Glycerophospholipid Analysis}

Total lipids were extracted from abdominal muscle tissues by the method of Folch et al. (1957). Individual phospholipid classes and their molecular species were quantified by a triple quadrupole Qtrap 6500, ABSciex (Les Ulis, France) in tandem with a Shimadzu Nexera XR liquid chromatography system (Shimazu France, Marne la Vallée, France). A YMC-Pack PVA-Sil, bonded with a monomolecular polymer coating of vinyl alcohol (PVA) (Particle size : $5 \mu \mathrm{m}$ Pore size : $120 \AA$, Usable pH range : 2.0-9.5 ; (YMC, Japan)) was used to separate the different lipid classes. Concentrations of the lipid compounds (including PE, PC, SM) were determined by comparing the peak area of each complex lipid with that of standards added with a known quantity. In total, 108 complex lipid compounds were quantified. The method is fully described in Wolf \& Quinn (2008) and in Lamaziere et al. (2011).

\section{Statistical analysis}

In order to provide a broad view of the variations between the lipidomes of the shrimps in response to the two pressure conditions, Principal Component Analyses (PCA) were performed using RStudio software (1.1.4 version, packages ggplot2, factoextra, factoMineR, 2018 versions). The analysis was performed on both concentration and percentage data for the fatty acids and the complex lipids. This analysis also allowed to spot if any particular contamination occurred in some samples, by detecting outliers in the scores plot. 
Following the PCAs, and in order to focus on the lipidome differences driven by pressure changes only, Orthogonal Projections to Latent Structures Discriminant Analyses (OPLS-DA) were then performed on the same data, using SIMCA 15.0 software (Umetrics, Umeå). The OPLS-DA, introduced by Trygg \& Wold (2002), is a multivariate analysis for omics datasets, which helps to understand what distinguishes two groups of samples according to the factors that vary between them. It is an extension to the supervised PLS regression method (Wold \& Martens, 1983), which removes variation from $\mathrm{X}$ (descriptor variables, here each lipid compound proportion or concentration) that is not correlated to $\mathrm{Y}$ (the variable to explain, here the pressure condition) in the first component of the model. Therefore, it is supposed to generate models easier to interpret compared to those generated by PLS-DA (Checa et al., 2015, Trygg \& Wold, 2002). The importance of variables on projection for the predictive component values (VIPpred) for the generated models were then calculated in order to detect which lipid compounds (fatty acids and complex lipids) were most responsible for the separation of the two groups of shrimps. They provide a score value for each independent variable $\mathrm{X}$ summarizing their importance in the projection used by the PLS model to explain Y (Checa et al., 2015, Galindo-Prieto et al., 2014). Hence, the higher the VIPpred score of a variable, the more important for the explanation of Y. VIP values higher than one are generally admitted to consider a variable as significantly important (Chong \& Jun, 2005; Sun et al., 2012). Data were mean-centered and variance-scaled prior to PCA and PLS-DA multivariate analyses.

We subsequently tested the difference in mean proportion between the groups of pressure for the individual fatty acids (see Table 1). Data were tested with Shapiro-Wilks in order to evaluate their distribution. If the distribution was not normal, a non-parametric Wilcoxon-Mann Whitney test was applied. If the distribution was normal a t-test or a Welch test (if the variances of the two groups were different) was performed. All statistics were performed using an $\alpha$-level of 0.05. These tests were performed using RStudio software.

In the case of groups of variables (sum of the saturated, mono-unsaturated, and poly-unsaturated fatty acids, shown in Figure 2), the two experimental groups were statistically compared, however without using Bonferroni corrections. Although debated among statisticians (Nakagawa, 2004), the use of such corrections accounts for the inflation of type I errors in multiple testing. The statistical power of the corresponding results has therefore not passed the rigor of Bonferroni corrections, however these data were not central in our approach, they were rather used as comparison points with other studies. 


\section{RESULTS}

\section{1 \\ Overview of $M$. fortunata lipidomic response to acclimation pressure}

The two groups of shrimp samples form two separated clusters in the first two PCA components performed on the concentration data for the fatty acids and the complex lipid contents (Figures S1-S2 in supplementary material). The two groups were segregated in two clusters opposed on a diagonal plan regarding their fatty acids concentrations, while they were opposed on the first axis regarding their complex lipid concentrations. No strong outlier was detected. The loading plots (not shown) and the raw data suggested that this clear segregation could be explained by generally higher lipid concentrations in BOX shrimps, with respect to AP shrimps. Indeed, mean concentration of fatty acids of BOX shrimps was $1317+/-283 \mathrm{ng} / \mathrm{mg}$ while that of AP shrimps was 590 +/- $380 \mathrm{ng} / \mathrm{mg}$. Similarly, the muscle of BOX shrimps contained higher levels of PE (431 +/189 against $189+/-85$ nanoM/mg) and PC (144 +/- 18 against 67 +/- 15 nanoM/mg). A similar trend was observed for sterol levels $(9.56+/-2.11$ nanoM/mg for BOX against $7.60+/-3.57$ nanoM/mg for AP shrimps), and also for SM levels (12.92 +/- 2.12 nanoM/mg for BOX, vs. 11.16 +/- 1.86 nanoM/mg for AP shrimps).

The two groups of shrimps also formed two distinct groups when the PCA analyses were performed on data expressed as percentage of total lipid fatty acids, in order to avoid size effects due to concentration differences (Figures S3-S4 in supplementary material). In the subsequent OPLS-DA regarding fatty acid percentages, the two groups of shrimps segregated through the first two components regarding their fatty acid compositions (Figure 1). In the score plot of the OPLSDA performed on complex lipid compositions, the two groups were also well separated (Figure S5 supplementary material). The two AP and BOX groups exhibited important phenotype dissimilarities leading to a clear segregation of the observations in the variability plane (first two components). 

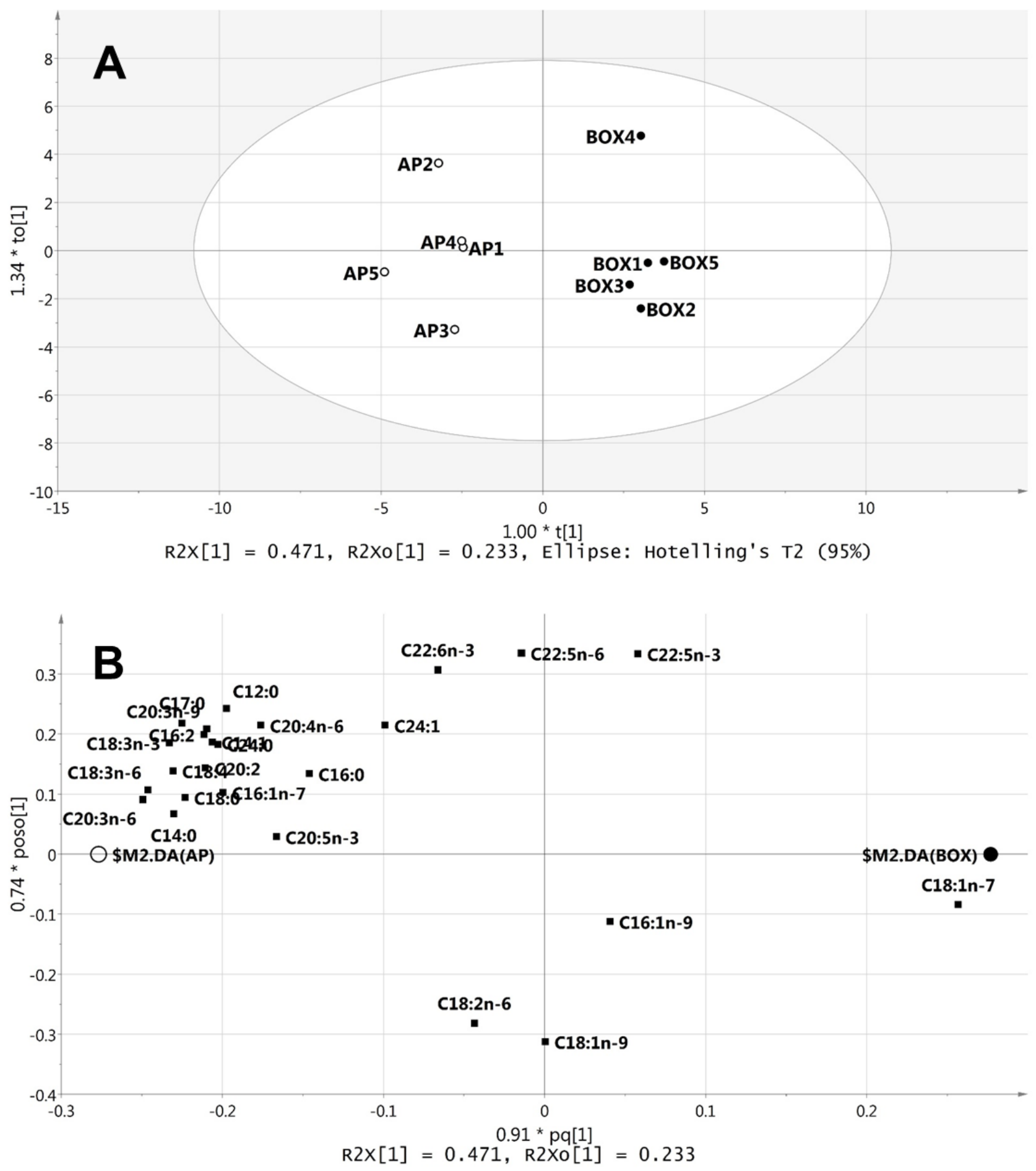

Figure 1: OPLS-DA score plot (A) and load plot (B) of the total fatty acids composition (\% weight) from Mirocaris fortunata muscle samples exposed to two pressure conditions, atmospheric pressure (AP open circles, $n=5$ ) and $18 \mathrm{MPa}$ (BOX full black circles, $\mathrm{n}=5$ ). Goodness of fit $R^{2}=0.704$, goodness of prediction by cross validation $Q^{2}=0.846$. In $B$, large circles represent the epicentre of shrimp observation groups, noted \$M2.DA(AP) and \$M2.DA(BOX) for AP and BOX shrimp groups, respectively. 


\begin{tabular}{|c|c|c|c|c|c|c|c|}
\hline$\%$ weight & BOX & SD & AP & SD & trend & p-value & Food \\
\hline C12:0 & 0,21 & 0,13 & 0,48 & 0,28 & & & 0,06 \\
\hline C14:0 & 0,46 & 0,22 & 1,29 & 0,44 & UP & $* *$ & 1,60 \\
\hline C14:1 & 0,02 & 0,01 & 0,06 & 0,02 & UP & $*$ & 0,03 \\
\hline C16:0 & 15,04 & 2,02 & 16,93 & 1,11 & & & 6,53 \\
\hline C16:1n-9 & 5,04 & 1,70 & 4,60 & 0,85 & & & 3,02 \\
\hline C16:1n-7 & 0,08 & 0,01 & 0,12 & 0,03 & UP & * & 0,17 \\
\hline C16:2 & 0,03 & 0,01 & 0,06 & 0,02 & UP & * & 0,28 \\
\hline C17:0 & 0,12 & 0,04 & 0,23 & 0,05 & UP & $*$ & 0,08 \\
\hline C18:0 & 1,69 & 0,45 & 2,72 & 0,47 & UP & $* *$ & 0,85 \\
\hline C18:1n-9 & 10,66 & 3,44 & 10,57 & 1,89 & & & 5,78 \\
\hline C18:1n-7 & 23,12 & 1,54 & 13,14 & 2,03 & DOWN & $* *$ & 5,94 \\
\hline C18:2n-6 & 1,73 & 0,33 & 1,96 & 0,75 & & & 2,93 \\
\hline C18:3n-6 & 0,13 & 0,01 & 0,23 & 0,04 & UP & $* *$ & 0,55 \\
\hline C18:3n-3 & 0,07 & 0,04 & 0,23 & 0,09 & UP & $* *$ & 0,00 \\
\hline C18:4 & 0,08 & 0,01 & 0,17 & 0,05 & UP & $* *$ & 1,94 \\
\hline C20:2 & 0,10 & 0,02 & 0,14 & 0,01 & UP & $*$ & 0,02 \\
\hline$C 20: 3 n-9$ & 0,07 & 0,02 & 0,12 & 0,05 & & & 0,02 \\
\hline$C 20: 3 n-6$ & 0,04 & 0,00 & 0,08 & 0,02 & & & 0,00 \\
\hline$C 20: 4 n-6$ & 0,68 & 0,16 & 1,01 & 0,29 & UP & * & 0,20 \\
\hline$C 20: 5 n-3$ & 22,16 & 3,65 & 26,15 & 2,24 & & & 46,38 \\
\hline$C 22: 5 n-6$ & 0,09 & 0,05 & 0,09 & - & & & 0,04 \\
\hline$C 22: 5 n-3$ & 0,63 & 0,15 & 0,58 & 0,12 & & & 0,59 \\
\hline$C 22: 6 n-3$ & 17,43 & 2,83 & 18,66 & 2,10 & & & 22,81 \\
\hline C24:0 & 0,11 & 0,09 & 0,30 & 0,13 & & & 0,05 \\
\hline C24:1 & 0,29 & 0,08 & 0,38 & 0,14 & & & 0,13 \\
\hline
\end{tabular}

321 Table 1: Average fatty acid composition (\% weight) of the Mirocaris fortunata and food lipid data 322 set. Trends between BOX ( $\mathrm{n}=5$ ind.) and AP ( $\mathrm{n}=5$ ind.) shrimps are indicated (* symbol : $\mathrm{p}$-value $323<0.05, * *$ symbol : p-value $<0.01)$ 


\section{Total fatty acid membrane composition}

25 fatty acids were detected in the analysis (Fig. 1A, and Table 1). The AP shrimps contain a significantly higher proportion of saturated fatty acids than BOX shrimps (mean values : $21.95 \%$ and $17.58 \%$, respectively, $\mathrm{p}$-value $=0.013$ ), and a significantly lower proportion of monounsaturated fatty acids (mean values : $28.86 \%$ and $39.22 \%$, respectively, p-value $=0.011$ ) (Figure 2). No difference was detected between BOX and AP shrimps levels of poly-unsaturated fatty acids $(\mathrm{p}$-value $=0.062)$.

Five predominant fatty acids each exceeded $10 \%$ of the composition, and accounted for 86.9 $\%$ in terms of proportion : C16:0 (15.98\% on average in all the shrimps), C18:1 n-7 (18.13\% on average), C18:1 n-9 (10,61\% on average), C20:5 n-3 (known as "EPA") (24.15\% on average) and C22:6 n-3 (known as "DHA") (18.4\% on average) (Table 1). No significant difference was found between the levels of these predominant fatty acids within the two groups of shrimps, except for C18:1 n-7, a MUFA. AP shrimps' proportions of C18:1 n-7 were significantly lower than for BOX shrimps (mean values : $13.14 \%+/-2.03$, and $23.12 \%+/-1.54$ respectively, p-value $=0.008$ ). In the OPLS-DA load plot (Fig. 1B), this fatty acid appeared to strongly discriminate the two experimental groups. C18:1 n-7 also displayed the highest VIPpred score value (1.51) in the OPLSDA model performed on the fatty acid compositions (not shown). C18:1 n-7 alone is likely to account for the higher proportion of MUFAs in BOX shrimps (Table 1, Fig. 2), as no other predominant fatty acid seemed to vary between the two groups. The other most discriminating fatty acids between the two groups of shrimps (according to their VIPpred values $>1$, not shown), were C18:3 n-6, C18:0, C14:0, C18:3 n-3, C17:0, C16:2, C14:1, C20:2, C18:4, C16:1 n-7, C20:4 n-6. They were all present in proportions smaller than $3 \%$ in the muscle of the shrimps, and these proportions were all significantly higher in AP shrimps (Table 1). Finally, the food was analyzed and two major components appeared to exceed $10 \%$ of the total composition : C20:5 n-3 (EPA, $46.38 \%$ ) and C22:6 n-3 (DHA, $22.82 \%)$.

\section{Fatty acid metrics conventionally used to assess membrane order}

The average chain length (ACL) index, introduced by Poynter et al. (1989) was calculated as follows for each shrimp sample: $\mathrm{ACL}=(\Sigma[\mathrm{Ci}] \times \mathrm{i}) / \Sigma[\mathrm{Ci}]$, where [ $\mathrm{Ci}]$ is the concentration of the fatty acids containing i carbon atoms. Average ACL index was $18.65+/-0.19$ for BOX shrimps, and $18.68+/-0.13$ for AP shrimps. The saturation ratio and unsaturation index were also calculated according to Cossins \& MacDonald (1986), i.e. the ratio of the weight \% of saturated to unsaturated fatty acids (for saturation ratio), and the sum of weight $\%$ multiplied by the number of double bonds for each component (for unsaturation index) . The saturation ratio was $0.214+/-0.038$ 
360 for BOX shrimps, and $0.282+/-0.027$ for AP shrimps. Finally, the unsaturation index was 265.7 $361+/-24.7$ for BOX shrimps, and $284.7+/-15.9$ for AP shrimps.

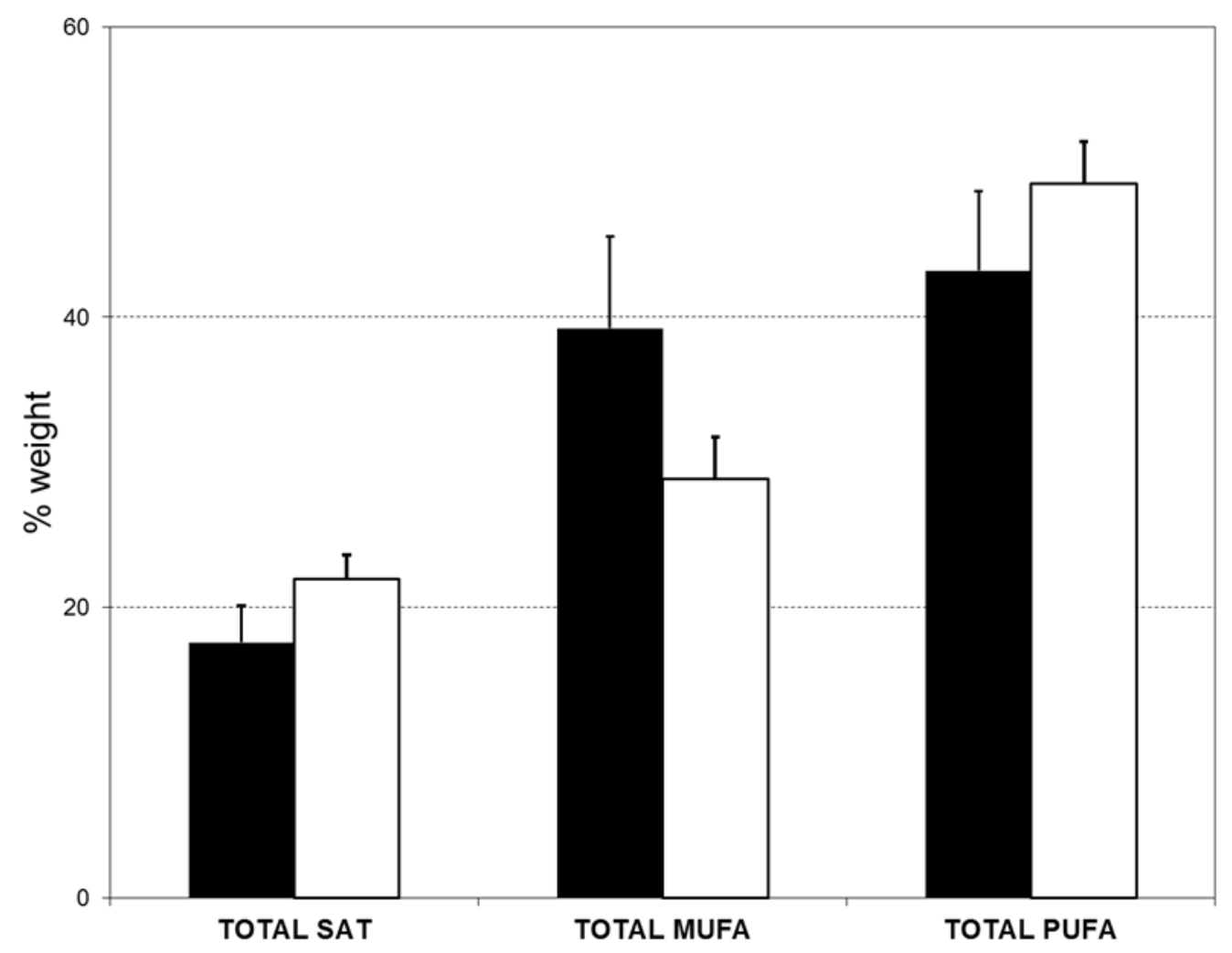

363

364 365 366 367 368 369 


\section{Complex lipid membrane composition}

108 complex lipids were detected in the analysis, which targeted phosphatidylethanolamine (PE, 44 molecular species detected, including ether-PE (PE-O, 14 molecular species)), phosphatidylcholines (PC, 44 molecular species detected, including ether-PC (PC-O), 13 species), sphingomyelins (SM, 15 molecular species detected), and sterols (5 molecular species detected). For one sample (AP3), the sterol analysis could not be achieved for technical reasons, and therefore this individual observation was removed for the calculation of the following complex lipid proportions (molar \%, Figure 3). Phosphatidylethanolamine (PE) was the dominant class in both groups of samples, accounting for $70.3+/-7.6 \%$ of complex lipid data composition in BOX shrimps, and $67.8+/-11.7 \%$ in AP shrimps (Fig. 3). Remarkably, these proportions were the addition of $33.0 \%$ of ether-link PE (PE-O) and $37.3 \%$ of ester-link PE for BOX shrimps, while they broke down in $42.3 \%$ of ether-link PE (PE-O) and $25.5 \%$ of ester-link PE, for AP shrimps. Phosphatidylcholines (PC) represented $25.6+/-6.5 \%$ of complex lipid data composition of the BOX shrimps and $24.3+/-8.2 \%$ of that of the AP shrimps. BOX shrimps contained $2.4+/-0.9 \%$ of sphingomyelin (SM), while AP ones contained $4.7+/-2.3 \%$. Finally, sterols account for $1.7+/-$ $0.4 \%$ in BOX shrimps and $3.2+/-1.5 \%$ in AP shrimps.

The VIPpred scoring of the OPLS-DA was performed on the complex lipids proportion dataset (Figure 4), in order to understand which lipid compounds separated the two groups (Fig. S5 supplementary material). Figure 4 displays the 44 variables with VIPpred values higher than 1. Among the latter, 9 were sphingomyelins, all of which were dominant in the AP shrimps. All the detected sterols appeared in this figure (Cholesterol, 7-Lathosterol, Desmosterol, 7-DHC, 8-DHC), and were all present in higher proportions in the AP shrimps. Moreover, 23 phosphatidylethanolamines were contained in this list. Among them, the 8 that include an ether link (PE O) were more abundant in proportion in AP shrimps and the great majority of the others (14/15), which include an ester link (PE), were more abundant in proportion in BOX shrimps. For seven phosphatidylethanolamines, the ether (PE-O) and corresponding ester (PE) species were both present in the list. This list also included seven PC (all ester species), 3 of which were found in larger proportion in AP shrimps samples, while the 4 other ones displayed higher levels in BOX shrimps. 


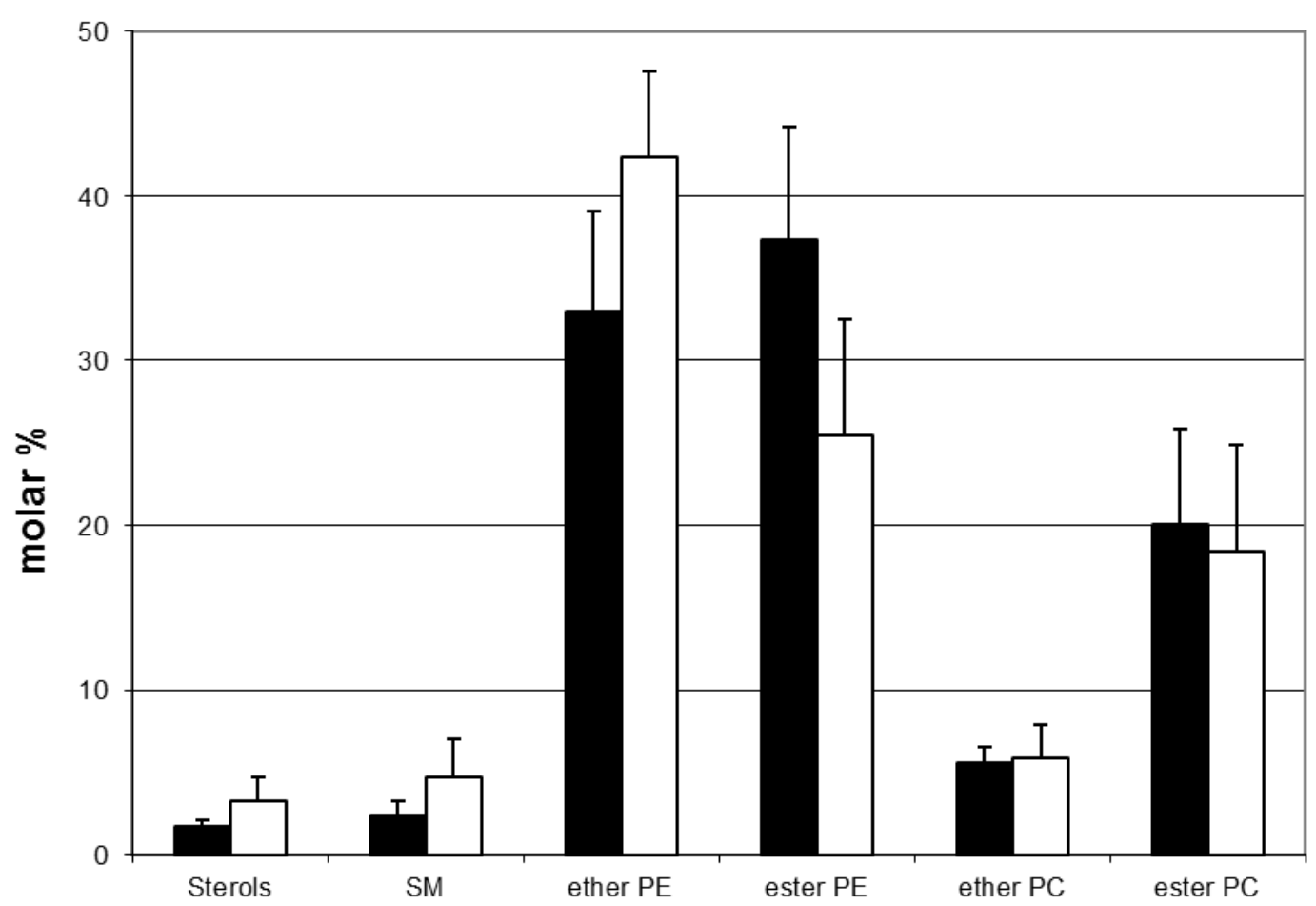

402

403

404

405 Figure 3: Complex lipids composition (molar \%) of the data sets from Mirocaris fortunata muscle 406 after five months maintained at atmospheric pressure (AP, white bars, $n=4$ ) or natural pressure $407(18 \mathrm{MPa})$ in the Abyssbox $(\mathrm{BOX}$, black bars, $\mathrm{n}=5)$. Mean values are shown and error bars 408 correspond to the standard deviation.

409

410 


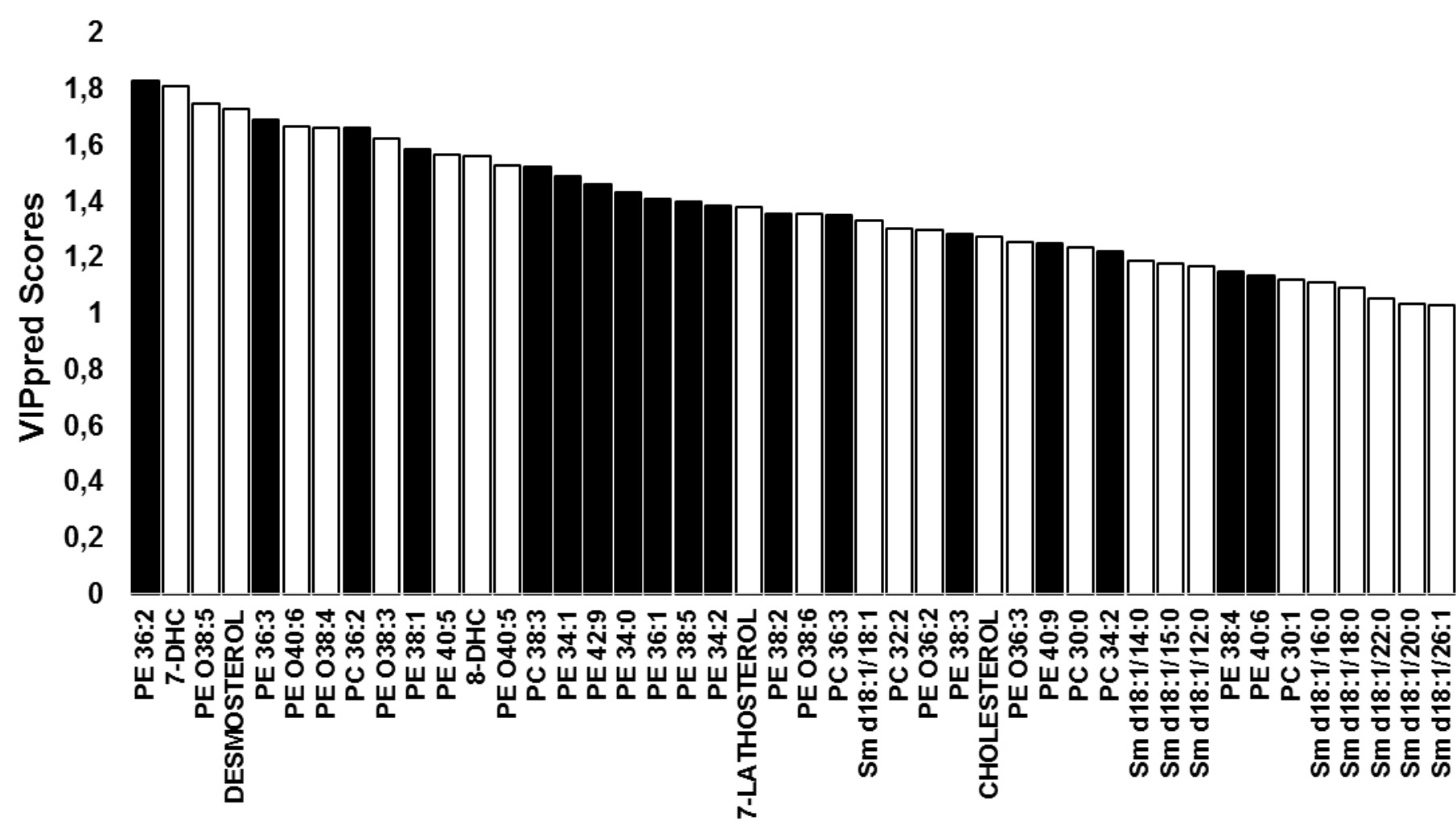

413 Figure 4: List of the variable importance for the projection (VIP) for the predictive components 414 with scores higher than 1 (arbitrary unit). These VIPs refer to the OPLS-DA performed on \% 415 composition of complex lipids raw data. Each lipid molecular species is colored according to its 416 relative abundance within specific experimental conditions: white/black bars indicate higher levels 417 at atmospheric pressure (AP shrimps, $n=4) / 18 \mathrm{MPa}(\mathrm{BOX}$ shrimps, $\mathrm{n}=5$ ) respectively. 


\section{DISCUSSION}

The aim of the present work was to test whether the successful acclimation of a deep-sea shrimp at two different pressures would allow to observe significant changes in membrane lipid composition, as expected according to the concept of homeoviscous adaptation (review in Ernst et al., 2016).

\section{The experimental context}

To our knowledge, it is the first time that lipidomic analyses have been conducted following long-term acclimation (i.e. several months) of deep-sea animals in captivity. The shrimps studied here had reached the Oceanopolis aquarium in July 2013 at the latest, and were sampled in December 2014, meaning a minimum acclimation period of 17 months, with identical food during the last five months.

While the AP group was maintained at atmospheric pressure, the BOX group was kept at its natural hydrostatic pressure, corresponding to the depth of the site of origin (1700-1800 m, Shillito et al., 2015). Except for hydrostatic pressure, our aim was to minimize environmental differences which could influence lipid compositions of the studied animals. Water chemistry, temperature and diet were the three main issues identified. Regarding nutrition, it is a well-known fact that lipid composition of an organism is directly influenced by the fatty acid content of its food, justifying the widespread use of fatty acids as tracers in trophic webs (review in Kelly \& Scheibling, 2012). Therefore identical food was provided to both BOX and AP shrimps during the last five months prior to lipid analyses, in order to erase any differential diet effect on lipid composition. As to the thermal environment, it is also well established that habitat temperature has a direct effect on lipid composition of poikilothermic organisms (Ernst et al., 2016). In our experimental context, the global temperature was $10^{\circ} \mathrm{C}$, however for both groups a "hotspot" was provided $\left(24-27{ }^{\circ} \mathrm{C}\right)$, and AP and BOX shrimps were often seen aggregating on it, between periods of swimming or feeding activity within the $10^{\circ} \mathrm{C}$ environment (Matabos et al., Shillito et al., 2015). Therefore a possible effect of temperature on lipid composition cannot be ruled out, since we have no certainty on the actual thermal regime experienced by the experimental animals. It should be noted however that Mirocaris fortunata is a fairly eurythermal hydrothermal vent shrimp, with recorded habitat temperature ranging from 4 to $24{ }^{\circ} \mathrm{C}$ in situ (Desbruyères et al., 2001). Finally, regarding water chemistry, care was taken that both groups were supplied through the same seawater line. 


\section{Higher levels of $\mathrm{FA}$ and complex lipids in pressurised samples (BOX)}

The concentration data (in $\mathrm{ng} / \mathrm{mg}$ or nanomol/mg, as opposed to relative data, in \%) showed that the shrimps maintained at natural pressure (BOX shrimps, $18 \mathrm{MPa}$ ) were more concentrated in lipid compounds than those maintained at atmospheric pressure (AP shrimps, 0.1 MPa). Overall, mean concentration of fatty acids of BOX shrimps was two-fold of that of AP shrimps (1317 vs. $590 \mathrm{ng} / \mathrm{mg}$ ), as for PE (431 vs. 189 nanoM/mg) and PC (144 vs. 67 nanoM/mg) levels. Such a trend was already observed when comparing different animal species from various habitat depths (shrimps : Yerlikaya et al., 2013, or other animal species, Bockus \& Seibel, 2016). The reasons for such a phenomenon are unclear: although hydrostatic pressure was proposed as one among several possible drivers of this phenomenon, ecological factors such as food limitation yielding increased lipid storage were also proposed. In our case study, variations of the complex lipid species PE and PC show that this response involves membrane contents, rather than lipid reserves. The decrease in lipid levels in AP shrimps could then correspond to a limited microvilli or endomembrane system synthesis, or lower cell divisions rates, at atmospheric pressure. Further structural studies (using electron microscopy) would certainly help to test this hypothesis at the subcellular level.

\section{The major FA components}

Four of the five major FA found in our samples showed no significant variation between the two experimental treatments. Among these, the two PUFA EPA (C20:5 n-3 / 24.15 \%) and DHA (C22:6 n-3 / $18.4 \%$ ) display levels which may appear unusually high for adult hydrothermal vent fauna. The interpretation for lower levels in the wild (absence in several mid-Atlantic ridge animals, Colaço et al., 2007, Zhu et al., 2015, or less than 6\% for adult Mirocaris shrimp, Pond et al., 1997, and adult Rimicaris shrimp, Streit et al., 2015) is that EPA and DHA are considered as markers of a photosynthetically-derived diet, of planktonic origin (Kelly \& Scheibling 2012, Parrish, 2013). Therefore, they are rare in the hydrothermal vent food web, which is based on bacterial chemosynthesis (Colaço et al., 2007). The higher levels observed in our experimental specimens likely correspond to the EPA and DHA enrichment of the diet proposed in captivity (46 and 23\% respectively, see Table 1). The two other major FA that did not show significant variation between our experiments are the SFA C16:0 (15.98 \%), and the MUFA C18:1 n-9 (10.61\%). Such levels of these FA are commonly observed in marine organisms (Kelly \& Scheibling 2012, Parrish, 2013), including vent fauna (Colaço et al., 2007). 
Finally, only one major FA showed a significant variation, the MUFA C18:1n-7 (vaccenic acid), reaching $23.12 \%+/-1.54$ for natural pressure acclimation, and $13.14 \%+/-2.03$ for atmospheric pressure acclimation (Table 1). In trophic studies, this FA is a common dietary tracer (Kelly \& Scheibling 2012, Parrish, 2013) and for example the ratio C18:1n-9/C18:1n-7 may be used to discriminate carnivory from detritivory in deep-sea fauna (Drazen et al., 2008). At deep-sea vents, vaccenic acid appears as a major component in several species (Streit et al., 2015, Colaço et al., 2007), including Mirocaris (in the 6 to $21 \%$ range, Pond et al., 1997). In the wild, these high levels reflect the importance of food sources of bacterial origin, in the chemosynthetically-based vent trophic web (Kelly \& Scheibling 2012). In the present study, shrimps were in captivity and fed with industrial food pellets, which contain a significant amount of C18:1n-7 (about 6\%, Table 1). Whether vaccenic acid in Mirocaris is here of endogenous or exogenous origin remains to be determined. However, given that identical diet was provided in both experiments (AP and BOX), the observed variation can not be explained by a diet effect.

In bacteria, C18:1n-7 is common and strongly involved in the homeoviscous response to temperature, with an increased biosynthesis facing cold temperatures, resulting in lower membrane order to counteract the ordering effect of cold temperatures (reviews in Zhang \& Rock, 2008, Hulbert et al., 2014, Ernst et al., 2016). Recent studies demonstrated that for E. coli, C18:1n-7 played a "disordering" role, and was the major MUFA involved in the regulation of membrane order of this bacteria (Budin et al., 2018). Regarding a homeoviscous response to pressure, an increased level of C18:1n-7 was also observed in response to increasing cultivation pressure, in the case of a deep-sea bacteria (Allen et al., 1999). Accordingly, variations in the level of this unsaturated FA impact membrane order, lower levels meaning higher order ("rigidifying effect"), and vice-versa. The important variation of vaccenic acid observed in our experiment is consistent with a homeoviscous response: exposed to atmospheric pressure, the shrimps displayed lower levels of C18:1n-7, in order to counteract the disordering ("fluidizing") effect of lower pressure. We therefore propose the existence of a homeoviscous response in the animals studied here, although further measurements of membrane order and composition in our experimental conditions are necessary for a complete demonstration.

Finally, it is interesting to note that $\mathrm{C} 18: 1 \mathrm{n}-7$ (vaccenic acid) belongs to the same biosynthetic pathway as the FA C16:1n-7 (Kelly \& Scheibling 2012) observed at greater levels in deep nematods (Van Campenhout et al., 2016) and fishes (Radnaeva et al., 2017), with respect to shallower species. Whether this pathway (desaturation of C16:0 towards C16:1n-7, followed by elongation towards $\mathrm{C} 18: 1 \mathrm{n}-7$ ) was shut down following acclimation to atmospheric pressure (AP 
samples), or whether C18:1n-7 was selectively accumulated through diet at natural pressure (BOX samples), remains to be investigated.

\section{The global response in FA composition}

The decrease in vaccenic acid levels observed upon acclimation to atmospheric pressure is likely responsible alone for the apparently lower levels of MUFA (Fig. 2, Table 1). This decrease occurred along with increases of several other fatty acids: an increase in SFA levels likely relates to the significant increases of C14:0, C18:0, and to a lesser extent C17:0 (Table 1, Fig. 2). These significant MUFA and SFA variations probably contribute to the apparently higher saturation ratio observed for atmospheric-pressure-acclimated shrimps (AP samples), and are also consistent with a homeoviscous response. Inversely, the situation seems unclear regarding PUFA variations: while several PUFA species clearly showed a marked up-regulation upon acclimation to atmospheric pressure (namely C18:3n-6, C18:3n-3, C18:4, and to a lesser extent C16:2, C20:2, and C20:4n-6, Table 1), these molecules nevertheless accounted for rather small proportions in the global compositions (less than 1\%), and displayed even smaller variations, as opposed to the ca. $10 \%$ variation observed for vaccenic acid. At a global level furthermore (Fig. 2), there was no apparent variation regarding either PUFA global levels (figure 3), or unsaturation index (265.7 +/- 24.7 vs. $284.7+/-15.9)$.

Most studies of lipid composition variations in response to increasing pressure and/or depth have emphasized a modulation of MUFA vs. SFA levels (increase vs. decrease), while the implication of PUFA variations is not clear. In the case of bacteria, some studies showed an involvement of PUFA (enhanced biosynthesis under increasing pressure, Delong \& Yayanos, 1986, Wang et al., 2014), while others did not (Delong \& Yayanos, 1985, Allen et al., 1999, Grossi et al., 2010). The situation also remains to be clarified regarding animals. In a study on antarctic copepods sampled in the wild at increasing depths (from the surface down to approximately $1000 \mathrm{~m}$ ), Pond et al. (2014) observed a significant decrease of SFA (consistent with our results) in the form of C16:0 and C18:0, but no specific variations of MUFA were mentioned (unlike our results). These studies also found a significant increase of the PUFA DHA (C22:6 n-3) with depth (not observed in our study), which they proposed to be consistent with homeoviscous adaptation theory. Another study on different fish species sampled from the surface down to $1600 \mathrm{~m}$ depth in lake Baikal lead to decreased levels of SFA, and increased levels of MUFA (both consistent with our results, and with a homeoviscous response, but here mainly due to C16:1n-7 and C18:1n-9 regarding MUFAs), yet another trend for PUFA (decrease, including DHA), in deeper species (Radnaeva et al., 2017). Another study comparing shallow-water and deep-sea nematod species (1300 $\mathrm{m}$ depth) lead to a similar trend, regarding SFA (decrease), and MUFA (increase, C16:1n-7 in particular), but here 
accompanied by an increase in PUFA levels (EPA and DHA in particular) for deeper species (Van Campenhout et al., 2016). PUFA may help regulate membrane order, as suggested from in vitro experiments (Guschina \& Harwood 2006), however their role in that respect remains to be clarified when dealing with whole animals sampled from the wild, with reduced knowledge on the environmental and nutritional histories, as opposed to laboratory experiments. In our laboratory study however, samples of the same species, fed for several months on identical diet, did not appear to use PUFAs to adjust to experimental conditions.

Finally, the average chain length (ACL) calculated for each FA composition (BOX vs. AP samples) remained unchanged (18.65 +/- 0.19 for BOX shrimps, and 18.68 +/- 0.13). Shifts in ACL have been observed as a possible response to membrane order perturbation, following environmental stress in bacteria (review in Yoon et al., 2015). Such a response does not seem to occur in our study.

\section{Variations in complex lipid composition}

As stated by Ernst et al. (2016), until now most studies have characterized the homeoviscous response with a specific focus on the acyl chain composition, involving their degree of saturation (relative compositions in terms of SFA MUFA PUFA). However, as a result of the development of quantitative lipidomics technology, an increasing number of studies emphasize the importance of complex lipidome variations of organisms facing changes in their thermal environment. To our knowledge, the complex lipid composition of organisms experiencing pressure variation has little been investigated so far, and hypotheses on lipid composition adjustments according to pressure are scarce. In this study, we examined the compositions in PC, PE, SM and sterols of our two shrimp pressure groups.

Cholesterol is known to regulate membrane order depending on its physical phase. It is supposed to favor the order in the liquid phase (Urbina et al., 1995, Ayee \& Levitan, 2016). But few studies report a correlation between pressure and cholesterol content in metazoans. Vettier et al. (2006) compared the cholesterol levels in the yellow and the silver stages of the European eel. The yellow eel is the pre-migratory stage that lives in shallow fresh-waters. It never encounters high pressure, contrary to the silver stage, which can be encountered at close to $1000 \mathrm{~m}$ depth during its spawning migration (Righton et al., 2016). They suggested that the three-fold lower cholesterol levels in silver eels could contribute in maintaining membrane order during their migration at depth. Similarly, reduced proportions of cholesterol found in phocids were believed to help them cope with high hydrostatic pressure while deep-diving (Williams et al., 2001). In our results, sterols (and particularly cholesterol) were among the most discriminating complex lipids between the two 
pressure groups (Fig. 4), representing on average $3.21 \%$ of the complex lipids in the AP shrimps, and $1.69 \%$ in the BOX shrimps (Fig. 3).

As for sterols, we observed that AP shrimps tend to have higher proportions of sphingomyelins than BOX shrimps on average (See Figs 3-4). Moreover, 9 out of the 15 detected sphingomyelins were important to discriminate the two groups, and all of them were dominant in AP shrimps (Fig. 4). This suggests that pressure also influences the SM levels. Finally, an intriguing discovery is that 8 discriminating ether PE were dominant in AP shrimps, while most of their corresponding ester versions (6) were dominant in BOX shrimps. It is interesting to note that in another study on yeast ether lipid deficient mutants (Shi et al., 2016), a reduction in C18:1n-7 levels was observed, suggesting that production of these compounds were regulated by the same mechanisms, in order to regulate membrane order. Also, the increase of ether lipids levels in response to increasing temperature has long been reported, and their role in the homeoviscous response was suggested to contribute to thermal compensation of membrane function (Hazel \& Williams, 1990).

Put together, cholesterol and sphingomyelins are known to be important components of ordered lipid domains originally named "rafts" (Simons \& Ikonen, 1997, Foster et al., 2003). More recently ether glycerophospholipids (PE species in particular), which also increase membrane order (Demediuk et al., 1983), were also shown to be components of these domains and were believed to stabilize these physical structures (Wallner \& Schmidz 2011, Braverman \& Moser, 2012; Tulodzekia et al., 2016, Koivuniemi, 2017, Dean \& Lodhi, 2018). Our data would thus be consistent with the hypothesis of a modulation of the organization of these domains through specific changes in the lipid signature of AP shrimps. This particular phenotype would possibly increase membrane stability to maintain appropriate traffic and cell signaling, in response to the disordering effect of lower pressure. Indeed, these domains were also known to be involved in many other biological processes, such as signaling processes or vesicle traffic (Foster et al., 2003). More than just contributing to structural stability, modifications in lipid fingerprints in AP shrimps might be involved in regulating several cell functions impaired by the acclimation to atmospheric pressure. A combined lipid/protein study, to further investigate the proteins, the regulation pathways commonly associated with these domains and the variation of their relative gene expressions would allow to test this hypothesis. 


\section{Conclusion}

This study provided new insights on the lipidomic response of organisms following acclimation to different pressures, and showed variations in lipid compositions, both at the fatty acids and the complex lipids levels. It is the very first time that this response has been studied in a deep-sea metazoan under long-term controlled conditions (pressure, temperature, food...), thanks to the use of rearing equipments at different pressures, a unique opportunity provided by the Océanopolis aquarium. It is also the first study reporting complex lipid variations in response to pressure acclimation. One limitation of our study is that the lipidomes are not exhaustive since several other complex lipids were not quantified (phosphatidylinositols, phosphatidylserines, ...), meaning a possible bias in the observed variations. However, the clear response in terms of vaccenic acid (C18:1n-7) variation, a molecule known to undoubtedly influence membrane order, strongly suggests the existence of a homeoviscous response (i.e. a regulation of the membrane's physical state) of Mirocaris fortunata following acclimation to atmospheric pressure. Whether the accompanying complex lipid variations participate to a homeoviscous adaptation remains to be determined. Further studies combining exhaustive lipidome determination and physical measurements of membrane fluidity under different pressure conditions are needed to make the link between these observations and membrane order. A complementary approach in order to better understand the mechanisms underlying this lipidomic response would be to target the enzymes involved in the production of the compounds which quantities differ, as well as follow the expression levels of the corresponding genes.

Finally, the study presented here compares the lipidomes of shrimps that have been maintained in captivity at different pressures, for several months. The observed lipidomic response undoubtedly illustrates an acclimation process, thereby demonstrating the phenotypic plasticity of these organisms regarding environmental variations. Further investigations should aim at evaluating the kinetics of this response, by measuring lipidome variations throughout the acclimation period. Bearing in mind that Mirocaris fortunata is found from $850 \mathrm{~m}$ to $4050 \mathrm{~m}$ depth, this would surely provide new knowledge on the capacity of these shrimps to distribute over such a large bathymetric range in the wild, and on their potential to undertake successful migrations towards yet unoccupied depths, in response to near-future climate changes. 


\section{ACKNOWLEDGEMENTS}

652 We wish to warmly thank Océanopolis staff members for their important contributions in shrimp 653 acclimation. We acknowledge the captains and crews of the oceanographic ships Thalassa 654 (Momarsat 2012 cruise) and Pourquoi Pas? (Biobaz 2013 cruises), and the pilots of Victor 6000 655 Remotely Operated Vehicle, for their dedicated assistance during sampling. We are also grateful to 656 G. Hamel, F. Lallier, M. Cannat, J. Blandin, P.-M. Sarradin, J. Sarrazin, P. Shillito, A. Colaço, and 657 R. Santos for scientific advice and support. We thank the two anonymous reviewers for their 658 important contribution to this manuscript. The AbyssBox project was funded by Océanopolis 659 Brest'Aim S.E.M., and this work also benefited from the support of the MIDAS European 660 Community project (European Union Seventh Framework Programme FP7/2007-2013) under the 661 grant agreement no. 603418. We also acknowledge initial financial support of the G.D.R. ECCHIS 662 (Ifremer, CNRS, UPMC). 
664

665

666 667

668

669

670

671

672

673

674

675

676

677

678

679

680

681

682

683

684

685

686

687

688

689

690

691

692

693

694

695

696

697

698

699

Allen, E. E., Facciotti, D., Bartlett, D. H. (1999). Monounsaturated but not polyunsaturated fatty acids are required for growth of the deep-sea bacterium Photobacterium profundum SS9 at high pressure and low temperature. Applied and Environmental Microbiology, 65(4), 1710-1720.

Ammendolia, J., Hamel, J.-F., Mercier, A. (2018) Behavioural responses to hydrostatic pressure in selected echinoderms suggest hyperbaric constraint of bathymetric range. Marine Biology , 165: 145. https://doi.org/10.1007/s00227-018-3399-7

Ayee, M.A., Levitan, I. (2016) Paradoxical impact of cholesterol on lipid packing and cell stiffness. Frontiers in Bioscience, Landmark, 21, 1245-1259. doi: 10.2741/4454

Barnes, D.K., Kuklinski, P. (2010) Bryozoans of the Weddell Sea continental shelf, slope and abyss: did marine life colonize the Antarctic shelf from deep water, outlying islands or in situ refugia following glaciations ? J. Biogeogr., 37, 1648-1656. doi:10.1111/j.1365-2699.2010.02320.x

Behan, M.K., Macdonald, A.G., Jones, G.R., Cossins, A.R. (1992) Homeoviscous adaptation under pressure: the pressure dependence of membrane order in brain myelin membranes of deep-sea fish, Biochimica et Biophysica Acta. 1103, 317-323

Bligh, E. G., Dyer, W. J. (1959). A rapid method of total lipid extraction and purification. Canadian Journal of Biochemistry and Physiology, 37(8), 911-917. https://doi.org/10.1139/o59-099

Bockus A., B., Seibel, B., A. (2016) Trimethylamine oxide accumulation as a function of depth in Hawaiian mid-water fishes. Deep-Sea Research I, $112: 37-44$

http://dx.doi.org/10.1016/j.dsr.2016.03.005

Braverman, N. E., Moser, A. B. (2012). Functions of plasmalogen lipids in health and disease. Biochimica et Biophysica Acta (BBA) - Molecular Basis of Disease, 1822(9), 1442-1452. https://doi.org/10.1016/j.bbadis.2012.05.008

Brown, A., Thatje, S. (2014) Explaining bathymetric diversity patterns in marine benthic invertebrates and demersal fishes: physiological contributions to adaptation of life at depth. Biol. Rev., 89, pp. 406-426. doi: 10.1111/brv.12061

Brown, A., Thatje, S. (2015). The effects of changing climate on faunal depth distributions determine winners and losers. Global Change Biology, 21(1), 173-180. https://doi.org/10.1111/gcb.12680 
Budin, I., De Rond, T., Chen, Y., Chan, L.J.G., Petzold, C.J., Keasling, J.D. (2018) Viscous control of 702 cellular respiration by membrane lipid composition. Science, 362, 1186-1189. DOI: 10.1126/ 703 science.aat7925

704

Cario, A., Grossi, V., Schaeffer, P., Oger, P. M. (2015). Membrane homeoviscous adaptation in the piezohyperthermophilic archaeon Thermococcus barophilus. Frontiers in Microbiology, 6, art. 1152. 708 https://doi.org/10.3389/fmicb.2015.01152

Checa, A., Bedia, C., Jaumot, J. (2015). Lipidomic data analysis: Tutorial, practical guidelines and applications. Analytica Chimica Acta, 885, 1-16. https://doi.org/10.1016/j.aca.2015.02.068

Carney, R. (2005). Zonation of Deep Biota on Continental Margins. In R. Gibson, J. Gordon, \& R. Atkinson (Eds.), Oceanography and Marine Biology (Vol. 20051650, pp. 211-278). CRC Press. https://doi.org/10.1201/9781420037449.ch6

Cossins, A. R., Macdonald, A. G. (1986) Homeoviscous adaptation under pressure. III. The fatty acid composition of liver mitochondrial phospholipids of deep-sea fish. Biochimica et Biophysica Acta, 860,

Chong, I.-G., Jun, C.-H. (2005). Performance of some variable selection methods when multicollinearity is present. Chemometrics and Intelligent Laboratory Systems, 78(1-2), 103-112. https://doi.org/10.1016/j.chemolab.2004.12.011

Clarke, A., Tyler, P.A. (2008) Adult Antarctic Krill Feeding at Abyssal Depths. Current Biology, 18, $282-$ 285, DOI 10.1016/j.cub.2008.01.059

Colaço, A., Desbruyères, D., Guezennec, J. (2007). Polar lipid fatty acids as indicators of trophic associations in a deep-sea vent system community. Marine Ecology, 28(1), 15-24. https://doi.org/10.1111/j.1439-0485.2006.00123.x $325-335$

Cottin, D., Brown, A., Oliphant, A., Mestre, N., Ravaux, J., Shillito, B., Thatje, S. (2012) Sustained hydrostatic pressure tolerance of the shallow water shrimp Palaemonetes varians at different temperatures: Insights into the colonisation of the deep sea. Comp. Biochem. Physiol., A, 162, 357-363. doi:10.1016/j.cbpa.2012.04.005 
Dean, J.M., Lodhi, I.J. (2018) Structural and functional roles of ether lipids. Protein and Cell, 9(2):196206. doi : 10.1007/s13238-017-0423-5

DeLong, E. F., Yayanos, A. A. (1985). Adaptation of the Membrane Lipids of a Deep-Sea Bacterium to Changes in Hydrostatic Pressure. Science, New Series, 228(4703), 1101-1103.

DeLong, E. F., Yayanos, A. A. (1986). Biochemical Function and Ecological Significance of Novel

Demediuk, P., Cowan, D.L., Moscatelli, E (1983) Effects Of Plasmenylethanolamine On The dynamic dispersions. A spin Label Study. Biochimica et Biophysica Acta, 730, 263-270

Bacterial Lipids in Deep-Sea Procaryotes. Applied Environmental Microbiology, 51, 4, 734-737.

Desbruyères, D., Biscoito, M., Caprais, J.-C., Colaço, A., Comtet, T., Crassous, P., ... Vangriesheim, A. (2001). Variations in deep-sea hydrothermal vent communities on the Mid-Atlantic Ridge near the Azores plateau. Deep Sea Research Part I: Oceanographic Research Papers, 48(5), 1325-1346. https://doi.org/10.1016/S0967-0637(00)00083-2

Desbruyères, D., Segonzac, M., \& Bright, M. (2006). Handbook of Deep-Sea Hydrothermal Vent Fauna (Second compl. rev. ed). Linz: Art \& Publishing.

Drazen, J.C., Phleger, C.F., Guest, M.A., Nichols, P.D. (2008) Lipid, sterols and fatty acids of abyssal polychaetes, crustaceans, and a cnidarian from the northeast Pacific Ocean: food web implications. Marine Ecology Progress Series, 372: 157-167. doi: 10.3354/meps07707

Ernst, R., Ejsing, C. S., \& Antonny, B. (2016). Homeoviscous Adaptation and the Regulation of Membrane Lipids. Journal of Molecular Biology, 428(24), 4776-4791. https://doi.org/10.1016/j.jmb.2016.08.013

Ernst, R., Ballweg, S. and Levental, I. (2018) Cellular mechanisms of physicochemical membrane homeostasis. Current Opinion in Cell Biology 2018, 53:44-51. doi.org/10.1016/j.ceb.2018.04.013

Fang, J., Zhang, L, Bazylinski D. A. (2010) Deep-sea piezosphere and piezophiles: geomicrobiology and biogeochemistry. Trends in Microbiology 18, 413-422.

Fernandes, P. M. B., Domitrovic, T., Kao, C. M., Kurtenbach, E. (2004). Genomic expression pattern in Saccharomyces cerevisiae cells in response to high hydrostatic pressure. FEBS Letters, 556(1-3), 153-160. https://doi.org/10.1016/S0014-5793(03)01396-6 
Folch, J., Lees, M., Sloane Stanley, G. H. (1957). A simple method for the isolation and purification of total lipides from animal tissues. The Journal of Biological Chemistry, 226(1), 497-509.

Foster, L. J., de Hoog, C. L., Mann, M. (2003). Unbiased quantitative proteomics of lipid rafts reveals high specificity for signaling factors. Proceedings of the National Academy of Sciences, 100(10), 5813-5818. https://doi.org/10.1073/pnas.0631608100

Fouquet, Y., Cherkashov, G., Charlou, J.-L., Ondreas, H., Cannat, M., Bortnikov, N., Silantyev, S., Etoubleau, J. (2008). Serpentine cruise - ultramafic hosted hydrothermal deposits on the Mid- Atlantic Ridge: First submersible studies on Ashadze 1 and 2, Logatchev 2 and Krasnov vent fields. InterRidge News, 2008, Vol. 17, 15-20.

Freitas, J.M., Bravim, F., Buss, D.S., Lemos, E.M., Fernandes, A.A.R., Fernandes, P.M.B. (2012) Influence of cellular fatty acid composition on the response of Saccharomyces cerevisiae to hydrostatic pressure stress. FEMS Yeast Research, 12, 871-878 DOI: 10.1111/j.1567-1364.2012.00836.x

Fumiyoshi, A. (2013) Dynamic structural changes in microbial membranes in response to high hydrostatic pressure analyzed using time-resolved fluorescence anisotropy measurement. Biophysical Chemistry, 183, 3-8 . doi.org/10.1016/j.bpc.2013.05.005

Galindo-Prieto, B., Eriksson, L., Trygg, J. (2014). Variable influence on projection (VIP) for orthogonal projections to latent structures (OPLS): Variable influence on projection for OPLS. Journal of Chemometrics, 28(8), 623-632. https://doi.org/10.1002/cem.2627

Grossi, V., Yakimov, M. M., Al Ali, B., Tapilatu, Y., Cuny, P., Goutx, M., ... Tamburini, C. (2010). Hydrostatic pressure affects membrane and storage lipid compositions of the piezotolerant hydrocarbondegrading Marinobacter hydrocarbonoclasticus strain \#5: Pressure dependent bacterial storage lipid formation. Environmental Microbiology, 12(7), 2020-2033. https://doi.org/10.1111/j.14622920.2010.02213.x

Guschina, I. A., Harwood, J. L. (2006). Mechanisms of temperature adaptation in poikilotherms. FEBS Letters, 580(23), 5477-5483. https://doi.org/10.1016/j.febslet.2006.06.066

Hazel, J. R. (1995). Thermal Adaptation in Biological Membranes: Is Homeoviscous Adaptation the Explanation? Annual Review of Physiology, 57(1), 19-42. https://doi.org/10.1146/annurev.ph.57.030195.000315 
Hazel, J. R., Williams, E. E. (1990). The role of alterations in membrane lipid composition in enabling physiological adaptation of organisms to their physical environment. Progress in Lipid Research, 29(3), 167-227. https://doi.org/10.1016/0163-7827(90)90002-3

Hulbert, A.J., Kelly, M.A., Abbott, S.K. (2014) Polyunsaturated fats, membrane lipids and animal longevity. J Comp Physiol B , 184:149-166 DOI 10.1007/s00360-013-0786-8

Jamieson, A.J., Fujii, T., Mayor, D.J., Solan, M. and Priede, I.G. (2010) Hadal trenches: the ecology of the deepest places on Earth. Trends in Ecology and Evolution, Vol.25 No.3, 190-197. doi:10.1016/j.tree.2009.09.009

Kelly, J.R., Scheibling, R.E. (2012) Fatty acids as dietary tracers in benthic food webs. Marine Ecology Progress Series, 446: 1-22. doi: 10.3354/meps09559

Koivuniemi, A. (2017) The biophysical properties of plasmalogens originating from their unique molecular architecture. FEBS Letters , 591, 2700-2713. doi:10.1002/1873-3468.12754

Lamaziere, A., Richard, D., Barbe, U., Kefi, K., Bausero, P., Wolf, C., et al., (2011) Differential distribution of DHA-phospholipids in rat brain after feeding: A lipidomic approach. Prostaglandins Leukot Essent Fatty Acids, 84, 7-11

Macdonald, A.G. (1997) Hydrostatic pressure as an environmental factor in life processes. Comparative Biochemistry and Physiology 116A, 291-297.

Martin, J. W., Christiansen, J. C. (1995). A new species of the shrimp genus Chorocaris Martin (Crustacea: Decapoda: Bresiliidae) from hydrothermal vent fields along the Mid-Atlantic Ridge. Proceedings of the Biological Society of Washington, 108, 220-227.

Matabos, M., Cuvelier, D., Brouard, J., Shillito, B., Ravaux, J., Zbinden, M., ... Sarrazin, J. (2015). Behavioural study of two hydrothermal crustacean decapods: Mirocaris fortunata and Segonzacia mesatlantica, from the Lucky Strike vent field (Mid-Atlantic Ridge). Deep Sea Research Part II: Topical Studies in Oceanography, 121, 146-158. https://doi.org/10.1016/j.dsr2.2015.04.008

Nakagawa, S. (2004) A farewell to Bonferroni: the problems of low statistical power and publication bias. Behavioral Ecology, Vol. 15, No. 6: 1044-1045. doi:10.1093/beheco/arh107 
Parent, G.J., Pernet, F., Tremblay, R., Sévigny, J.-M., Ouellette, M. (2008) Remodeling of membrane lipids in gills of adult hard clam Mercenaria mercenaria during declining temperature. Aquatic Biology, 3: 101109. doi: 10.3354/ab00073

Parrish, C.R. (2013) Lipids in Marine Ecosystems. ISRN Oceanography, 2013, 16. doi : $10.5402 / 2013 / 604045$

Pond, D.W., Segonzac, M., Bell, M.V., Dixon , D.R., Fallick, A.E., John, R., Sargent, J.R. (1997) Lipid and lipid carbon stable isotope composition of the hydrothermal vent shrimp Mirocaris fortunata: evidence for nutritional dependence on photosynthetically fixed carbon. Marine Ecology Progress Series, 157, 221-231.

Pond, D. W., Tarling, G. A., Mayor, D. J. (2014). Hydrostatic Pressure and Temperature Effects on the Membranes of a Seasonally Migrating Marine Copepod. PLoS ONE, 9(10), e111043. https://doi.org/10.1371/journal.pone.0111043

Poynter, J. G., Farrimond, P., Robinson, N., Eglinton, G. (1989). Aeolian-Derived Higher Plant Lipids in the Marine Sedimentary Record: Links with Palaeoclimate. In M. Leinen \& M. Sarnthein (Eds.), Paleoclimatology and Paleometeorology: Modern and Past Patterns of Global Atmospheric Transport (pp. 435-462). Dordrecht: Springer Netherlands. https://doi.org/10.1007/978-94-009-0995-3_18

Pradillon, F. (2012). High hydrostatic pressure environments. In E. M. Bell (Ed.), Life at extremes: environments, organisms and strategies for survival (pp. 271-295). Wallingford: CABI. https://doi.org/10.1079/9781845938147.0271

Priede, I. G., Froese, R. (2013). Colonization of the deep sea by fishes: colonization of the deep sea. Journal of Fish Biology, 83(6), 1528-1550. https://doi.org/10.1111/jfb.12265

Radnaeva, L. D., Popov, D. V., Grahl-Nielsen, O., Khanaev, I. V., Bazarsadueva, S. V., Käkelä, R. (2017). Fatty acid composition in the white muscle of Cottoidei fishes of Lake Baikal reflects their habitat depth. Environmental Biology of Fishes, 100(12), 1623-1641. https://doi.org/10.1007/s10641-017-0670-6

Ramirez-Llodra, E., Brandt, A., Danovaro, R., De Mol, B., Escobar, E., German, C.R., Levin, L.A., Martinez Arbizu, P., Menot, L., Buhl-Mortensen, P., Narayanaswamy, B.E., Smith, C.R., Tittensor, D.P., Tyler, P.A., Vanreusel, A., Vecchione, M. (2010) Deep, diverse and definitely different: unique attributes of the world's largest ecosystem. Biogeosciences, 7, 2851-2899, doi:10.5194/bg-7-2851-2010 
Righton, D., Westerberg, H., Feunteun, E., Okland, F., Gargan, P., Amilhat, E., ... Aarestrup, K. (2016). Empirical observations of the spawning migration of European eels: The long and dangerous road to the Sargasso Sea. Science Advances, 2(10), e1501694-e1501694. https://doi.org/10.1126/sciadv.1501694

Sarda, F., D’Onghia, G.-F., Politou, C.Y., Company, J.B., Maiorano, P., Kapiris, K. (2004) Deep-sea distribution, biological and ecological aspects of Aristeus antennatus (Risso, 1816) in the western and central Mediterranean Sea. Scientia. Marina., 68 (Suppl. 3): 117-127

Shi, X., Tarazona, P., Brock, T. , Browse, J., Feussner, I., Watts, J.L. (2016) A Caenorhabditis elegans model for ether lipid biosynthesis and function. J. Lipid Res. 57: 265-275. DOI 10.1194/jlr.M064808

Shillito, B., Le bris, N., Hourdez, S., Ravaux, J., Cottin, D., Caprais, J.-C., Jollivet, D., Gaill, F. (2006). Temperature resistance studies on the deep-sea vent shrimp Mirocaris fortunata. Journal of Experimental Biology, 209(5), 945-955. https://doi.org/10.1242/jeb.02102

Shillito, B., Ravaux, J., Sarrazin, J., Zbinden, M., Sarradin, P.-M., Barthelemy, D. (2015). Long-term maintenance and public exhibition of deep-sea hydrothermal fauna: The AbyssBox project. Deep Sea Research Part II: Topical Studies in Oceanography, 121, 137-145. https://doi.org/10.1016/j.dsr2.2015.05.002

Simons, K., Ikonen, E. (1997). Functional rafts in cell membranes. Nature, 387(6633), 569-572. https://doi.org/10.1038/42408

Sinensky, M. (1974). Homeoviscous Adaptation - A Homeostatic Process that Regulates the Viscosity of Membrane Lipids in Escherichia coli. Proceedings of the National Academy of Sciences, 71(2), 522-525. https://doi.org/10.1073/pnas.71.2.522

Somero, G. N. (1992). Adaptations to high hydrostatic pressure. Annual Review of Physiology, 54, 557577. https://doi.org/10.1146/annurev.ph.54.030192.003013

Streit, K., Bennet, S.A., VanDover, C.L., Coleman, M. (2015) Sources of organic carbon for Rimicaris hybisae: Tracing individual fatty acids at two hydrothermal vent fields in the Mid-Cayman rise. Deep-Sea Research Part I, 100, 13-20. http://dx.doi.org/10.1016/j.dsr.2015.02.003

Sun, X.-M., Yu, X.-P., Liu, Y., Xu, L., Di, D.-L. (2012). Combining bootstrap and uninformative variable elimination: Chemometric identification of metabonomic biomarkers by nonparametric analysis of 
discriminant partial least squares. Chemometrics and Intelligent Laboratory Systems, 115, 37-43. https://doi.org/10.1016/j.chemolab.2012.04.006

Trygg, J., Wold, S. (2002). Orthogonal projections to latent structures (O-PLS). Journal of Chemometrics, 16(3), 119-128. https://doi.org/10.1002/cem.695

Tulodziecka, K., Diaz-Rohrer, B.B., Farley, M.M., Chan, R.B., Di Paolo, G., Levental, K.R., Waxham, M.N., Levental, I. (2016) Remodeling of the postsynaptic plasma membrane during neural development. Molecular Biology of the Cell, 27, 3480-3489. doi/10.1091/mbc.E16-06-0420

Urbina, J. A., Pekerar, S., Le, H., Patterson, J., Montez, B., Oldfield, E. (1995). Molecular order and dynamics of phosphatidylcholine bilayer membranes in the presence of cholesterol, ergosterol and lanosterol: a comparative study using 2H-, 13C- and 31P-NMR spectroscopy. Biochimica et Biophysica Acta (BBA) - Biomembranes, 1238(2), 163-176. https://doi.org/10.1016/0005-2736(95)00117-L

Van Campenhout, J., Vanreusel, A. (2016). Closely related intertidal and deep-sea Halomonhystera species have distinct fatty acid compositions. Helgoland Marine Research, 70(1). https://doi.org/10.1186/s10152016-0467-6

Vettier, A., Labbe, C., Amerand, A., Da Costa, G., Le Rumeur, E., Moisan, C., Sebert, P. (2006). Hydrostatic pressure effects on eel mitochondrial functioning and membrane fluidity. Undersea \& Hyperbaric Medicine: Journal of the Undersea and Hyperbaric Medical Society, Inc, 33(3), 149-156.

Wallner, S., Schmitz, G. (2011) Plasmalogens the neglected regulatory and scavenging lipid species. Chemistry and Physics of Lipids, 164, 573-589 doi: 10.1016/j.chemphyslip.2011.06.008

Wang, J., Li, J., Dasgupta, S., Zhang, L., Golovko, M.Y., Golovko, S.A., Fang, J. (2014) Alterations in Membrane Phospholipid Fatty Acids of Gram-Positive Piezotolerant Bacterium Sporosarcina sp. DSK25 in Response to Growth Pressure. Lipids, 49:347-356. DOI 10.1007/s11745-014-3878-7

Williams, E. E., Stewart, B. S., Beuchat, C. A., Somero, G. N., Hazel, J. R. (2001). Hydrostatic-pressure and temperature effects on the molecular order of erythrocyte membranes from deep-, shallow-, and nondiving mammals. Canadian Journal of Zoology, 79(5), 888-894. https://doi.org/10.1139/cjz-79-5-888

Wirsen, C.O., Jannasch, H.W., Wakeham, S.G., Canuel, E.A. (1987) Membrane Lipids of a Psychrophilic and Barophilic Deep-sea Bacterium. Current Microbiology, 14 , pp. 319-322 
960

961

962

963

964 965

966

967

968

969

970

971

972

973

974

975

976

977

978 Zhang, Y.M., Rock, C.O. (2008) Membrane lipid homeostasis in bacteria. Nature reviews microbiology, 6, 979 222-233. doi:10.1038/nrmicro1839

980

981

982 983

Wold, S., Martens, H., Wold, H. (1983). The multivariate calibration problem in chemistry solved by the PLS method. In B. Kågström \& A. Ruhe (Eds.), Matrix Pencils (Vol. 973, pp. 286-293). Berlin, Heidelberg: Springer Berlin Heidelberg. https://doi.org/10.1007/BFb0062108

Wolf, C., Quinn, P.J. (2008) Lipidomics: practical aspects and applications, Prog Lipid Res, 47, 15-36

Yancey, P.H., Gerringer, M.E., Drazen, J.C., Rowden, A.A., Jamieson, A. (2014) Marine fish may be biochemically constrained from inhabiting the deepest ocean depths, Proc. Nat. Acad. Sci. vol. 111, 12, 4461-4465. doi/10.1073/pnas.1322003111

Yerlikaya, P., Topuz, O. K., Buyukbenli, H. A., Gokoglu, N. (2013). Fatty Acid Profiles of Different Shrimp Species: Effects of Depth of Catching. Journal of Aquatic Food Product Technology, 22(3), 290297. https://doi.org/10.1080/10498850.2011.646388

Yoon Y., Lee, H., Lee, S., Kima, S., Choi, K.-H. (2015) Membrane fluidity-related adaptive response mechanisms of foodborne bacterial pathogens under environmental stresses. Food Research International, 72 25-36. http://dx.doi.org/10.1016/j.foodres.2015.03.016

(22-233. doi:10.1038/nrmici

Zhu, S., Ye, M., Yan, X., Zhou, Y., Wang, C., Xu, J. (2015). Lipid Adaptation of Shrimp Rimicaris exoculata in Hydrothermal Vent. Lipids, 50(12), 1233-1242. https://doi.org/10.1007/s11745-015-4081-1 